\title{
Sulfatase 2 promotes breast cancer progression through regulating some tumor-related factors
}

\author{
CHENFANG ZHU $^{1 *}, \mathrm{LIU}_{\mathrm{HE}^{1 *}}, \mathrm{XIN} \mathrm{ZHOU}^{2}, \mathrm{XIN} \mathrm{NIE}^{1}$ and $\mathrm{YAN} \mathrm{GU}^{1}$ \\ ${ }^{1}$ Department of General Surgery, Shanghai Ninth People's Hospital \\ Affiliated with Shanghai Jiaotong University, School of Medicine, Shanghai 200011, P.R. China; \\ ${ }^{2}$ Department of Surgery, George Washington University, Washington, DC 20052, USA
}

Received October 15, 2015; Accepted December 2, 2015

DOI: $10.3892 /$ or.2015.4525

\begin{abstract}
In previous studies Sulf2 has been evidenced to play an important role in tumor progression through editing sulfate moieties on heparan sulfate proteoglycans (HSPGs) and modulating heparin binding growth factors. However, the role of Sulf 2 in breast cancer progression is still poorly understood. In the present study, we hypothesized that Sulf2 promoted breast cancer progression. Two different breast cancer cell lines, MCF-7 and MDA-MB-231, were chosen for this study because of high and low Sulf2 expression levels. We also altered their Sulf 2 expression by establishing Sulf2 knockdown and overexpressing breast cancer cell lines MCF-7 shSulf2 and MDA-MB-231 Sulf2. To evaluate the functions of Sulf2, cell proliferation, apoptosis, cell cycle, invasion, mobility and adhesion of these cell lines were measured in vitro, and xenograft formation, invasion and metastasis ability were examined in vivo. Furthermore, expression of related genes were screened and were certified in these cell lines. We found that Sulf2 increased breast cancer proliferation, invasion, mobility and adhesion both in vitro and in vivo. Sulf2 also decreased cisplatin inducing breast cancer apoptosis without affecting the cell cycle. Sulf2 upregulated c-fos induced growth factor (FIGF) and nuclear receptor subfamily 4 group A member 3 (NR4A3) expression and downregulated the cluster of differentiation 82 (CD82) and platelet-derived growth factor $\mathrm{C}$ (PDGFC) expression in breast cancer. Our data confirmed that Sulf 2 promoted breast cancer progression and regulated the expression of tumorrelated genes in breast cancer.
\end{abstract}

Correspondence to: Dr Yan Gu, Department of General Surgery, Shanghai Ninth People's Hospital, Affiliated with Shanghai Jiaotong University, School of Medicine, Shanghai 200011, P.R. China

E-mail: guyan_8@hotmail.com

*Contributed equally

Key words: Sulf2, breast cancer, proliferation, apoptosis, invasion, metastasis

\section{Introduction}

Breast cancer is the most common cancer among women in many countries. Surgery, chemotherapy, radiotherapy, endocrine therapy and targeted therapy significantly improve the disease-free survival and overall survival of patients with breast cancer (1). Molecular targeted treatment bring breast cancer treatment into the molecular therapy era, with the classification of breast cancer molecular subtypes and the detection of genetic mutations (2). However, local recurrence and distant metastasis of breast cancer are the most important factors in breast cancer treatment failure. The mechanisms of breast cancer metastasis and the molecular mechanisms of this progression are still not understood. Therefore, it is necessary to uncover new molecular targets in breast cancer.

Extracellular sulfatases, especially heparan endosulfatases (Sulfs), have attracted the attention of cancer researchers because of accumulating evidence that they may play important roles in cancer progression by modifying the sulfate patterns of HSPGs located on the surface of most animal cells. HSPGs can be released into the extracellular matrix and detected in serum (3-6). HSPGs carry out many structural and signaling functions through their ability to bind to diverse protein ligands, including growth factors such as vascular endothelial growth factor (VEGF), fibroblast growth factor-1 (FGF-1) and stromal cell-derived factor 1 (SDF-1) $(7,8)$. The progression of breast cancer growth and metastasis involves many factors, including matrix metalloproteinases, adhesion molecules and growth factors. Khurana et al (9) showed that Sulfs were involved in tumor invasion and metastasis by removing the $\mathrm{N}-3-\mathrm{O}$ and $6-\mathrm{O}$ sulfate amino glucose sulfuric acid from extracellular matrix HSPGs, thereby forming a 'common receptor'. We hypothesized Sulf 2 promoted breast cancer progression and would possibly be a new target in breast cancer treatment.

The Sulfs family includes Sulf1 and Sulf2, two structurally similar, endogenous sulfatases with different functions. They have highly conserved heparin-binding domains with $64 \%$ homology (10). At present, most studies have shown that Sulf1 is a tumor suppressor protein, but the role of Sulf2 in cancer progression is not uniform (10-12). Sulf2 is dysregulated in many cancers. It upregulates and promotes tumorigenesis in human hepatocellular (13), pancreatic (14), breast (15) and non- 
Table I. Sulf2 oligo sequences.

\begin{tabular}{|c|c|c|}
\hline No. & Sulf2 siRNA target & Sulf2 oligo sequence \\
\hline ShRNA-1 & GGAAGTATCTTAATGAATA & $\begin{array}{l}\text { 5'-TGCTGTTGACAGTGAGCGCCGGGAAGTATCTTAATGAATATAGTGAAGCCACA } \\
\text { GATGTATATTCATTAAGATACTTCCCGATGCCTACTGCCTCGGA-3' }\end{array}$ \\
\hline ShRNA-2 & GCGCCAACAATAACACGTA & $\begin{array}{l}\text { 5'-TGCTGTTGACAGTGAGCGACAGCGCCAACAATAACACGTATAGTGAAGCCAC } \\
\text { AGATGTATACGTGTTATTGTTGGCGCTGGTGCCTACTGCCTCGGA-3' }\end{array}$ \\
\hline ShRNA-3 & CCTTTGACATTTTGTAAAA & $\begin{array}{l}\text { 5'-TGCTGTTGACAGTGAGCGAAACCTTTGACATTTTGTAAAATAGTGAAGCCACA } \\
\text { GATGTATTTTACAAAATGTCAAAGGTTCTGCCTACTGCCTCGGA-3' }\end{array}$ \\
\hline ShRNA-4 & TGAAGCTGCATAAGTGCAA & $\begin{array}{l}\text { 5'-TGCTGTTGACAGTGAGCGCGCTGAAGCTGCATAAGTGCAATAGTGAAGCCAC } \\
\text { AGATGTATTGCACTTATGCAGCTTCAGCTTGCCTACTGCCTCGGA-3' }\end{array}$ \\
\hline
\end{tabular}

small cell lung carcinoma (16). Based on these studies, Sulf2 is considered a bona fide candidate cancer-causing agent in multiple cancer types. It could therefore be a therapeutic target for the treatment of non-small cell lung cancer (NSCLC) and other cancers (17), but other studies have shown conflicting results. Peterson et al (12) reported that Sulf2 overexpression in MDA-MB-231 cells inhibited breast cancer cell proliferation, invasion and metastasis in vitro, and the results were further confirmed in vivo. In the present study, we investigated the role of Sulf2 in breast cancer progression. We detected endogenous expression of Sulf 2 in several breast cancer cell lines using western blot analysis and selected two human breast cancer cell lines MCF-7 and MDA-MB-231, which respectively express Sulf 2 or not, to further study the role of Sulf2 in breast cancer. Two breast cancer cell lines were created for Sulf 2 function studies with stable knockdown or overexpression of Sulf2 (MCF-7 shSulf2 and MDA-MB-231 Sulf2, respectively).

\section{Materials and methods}

Cell lines. Human breast cancer cell lines (MCF-7,MDA-MB-231, MDA-MB-468 and BT-549) and mammary epithelial cell line HBL-100 were obtained from the Cell Bank of the Chinese Academy of Sciences (Shanghai, China). The HEK293T cells used for lentivirus packaging were stocked in our own laboratory. Cells were cultured in Dulbecco's modified Eagle's medium (DMEM; HyClone Laboratories, Logan, UT, USA) with $10 \%$ fetal bovine serum (FBS; Gibco, Grand Island, NY, USA) and penicillin-streptomycin (Gibco) at $37^{\circ} \mathrm{C}$ and $5 \% \mathrm{CO}_{2}$.

Sulf2 shRNA and overexpression vector constructs. To construct the short-hairpin Sulf2 vector, shSulf2 target sequences were determined using siRNA scales (http://gesteland.genetics.utah.edu/siRNA_scales/) and amplified using the primer pair miR30 XhoI (5'-CAGAAGGCTCGAGAAG GTATATTGCTGTTGACAGTGAGCG-3') and miR30 EcoRI (5'-CTAAAGTAGCCCCTTGAATTCCGAGGCAGTAGG CA-3') to introduce the miR-30 sequence and XhoI and EcoRI (MBI Fermentas, Vilnius, Lithuania) restriction sites flanking the shSulf 2 sequence. The amplified sequences were inserted into MLP vectors (Transomics, Shanghai, China) following XhoI and EcoRI digestion of both PCR fragments and MLP vectors. The newly constructed vectors were named shSulf2-1 to 4 (Table I). The silencing efficiency of shSulf2-1 to 4 was measured in MCF-7 breast cancer cells using western blot analysis.

To generate the Sulf2 overexpression construct, Sulf2 cDNA was amplified from the cDNA of MCF-7 cells using the forward primer 5'-CTAGCTAGCAAAAAAGAAGATG GGCCCCC-3' and reverse primer 5'-CGGGATCCTTAACC TTCCCAGCCTTCCC-3'. The amplified fragment was cloned into the $\mathrm{pCDH}$ vector (System Biosciences, Mountain View, $\mathrm{CA}, \mathrm{USA}$ ) to form the pCDH-Sulf2 overexpression vector construct. The sequences of these two positive clones were identified using enzyme digestion and gene sequencing detection (Shanghai Meiji, Shanghai, China).

Lentivirus was packaged in HEK293T cells using Lipofectamine 2000 (Life Technologies, Carlsbad, CA, USA), and transfection was performed following the manufacturer's instructions. The MCF-7 cell lines transfected with blank MLP vectors and shSulf2-1 were named as MCF-7 NC and MCF shSulf2. The MDA-MB-231 cell lines transfected with blank $\mathrm{pCDH}$ vector and $\mathrm{pCDH}-\mathrm{Sulf} 2$ were name as MDA-MB-231 vector and MDA-MB-231 Sulf2.

$q R T-P C R$ analysis. Total RNA was isolated from cells using TRIzol reagent (Invitrogen, Madison, WI, USA) and reverse transcribed into cDNA using SuperScript III Reverse Transcriptase (Invitrogen). The mRNA level was determined by 7900 HT qRT-PCR (Applied Biosystems, Foster City, CA, USA) using SYBR ${ }^{\circledR}$ Green Real-time PCR Master Mix (Takara, Shiga, Japan). Primers for qRT-PCR are listed in Table II. Glyceraldehyde-3-phosphate dehydrogenase (GAPDH) was used as an internal control. Relative mRNA levels were calculated using the $\Delta \Delta \mathrm{Ct}$ method.

Western blot analysis. Cell lysate was prepared as previously described and equal amount of protein was used in western blot analysis (18). Cells were harvested in RIPA lysis buffer (Beyotime Institute of Biotechnology, Shanghai, China), resolved in SDS-PAGE, transferred to polyvinylidene fluoride (PVDF) membrane and probed with antibodies: mouse antiSulf2 (2B4; Novus Biologicals, Littleton, CO, USA), rabbit anti-GAPDH (Sigma, St. Louis, MO, USA); rabbit anti-FIGF (PAB4879; Abnova, Atlanta, GA, USA), rabbit anti-PGF (PAB8004; Abnova), rabbit anti-CD82 (ab109529; Abnova), 
Table II. Real-time PCR primers.

\begin{tabular}{|c|c|c|}
\hline Gene & Primer sequences & Length (bp) \\
\hline GAPDH (control) & $\begin{array}{l}\text { Forward: 5'-GGGAAACTGTGGCGTGAT-3' } \\
\text { Reverse: 5'-GAGTGGGTGTCGCTGTTGA-3' }\end{array}$ & 299 \\
\hline Sulf2 & $\begin{array}{l}\text { Forward: 5'-GGCAGGTTTCAGAGGGACC-3' } \\
\text { Reverse: 5'-GAAGGCGTTGATGAAGTGCG-3' }\end{array}$ & 207 \\
\hline CD82 & $\begin{array}{l}\text { Forward: 5'-AGCAGAACCCGCAGAGTCC-3' } \\
\text { Reverse: 5'-GCTTCCTTCCACGAAACCA-3' }\end{array}$ & 101 \\
\hline FGFR4 & $\begin{array}{l}\text { Forward: 5'-GTTCTGCTCGGCTTCTTGG-3' } \\
\text { Reverse: 5'-ACGCCATTTGCTCCTGTTT-3' }\end{array}$ & 237 \\
\hline IGF1 & $\begin{array}{l}\text { Forward: 5'-TGGTGGATGCTCTTCAGTTCG-3' } \\
\text { Reverse: 5'-GCACTCCCTCTACTTGCGTTCT-3' }\end{array}$ & 265 \\
\hline NR4A3 & $\begin{array}{l}\text { Forward: 5'-GCTCGGAATACACCACGGA-3' } \\
\text { Reverse: 5'-GAAGGCTTGAGTTCGTAGTTGC-3' }\end{array}$ & 154 \\
\hline FIGF & $\begin{array}{l}\text { Forward: 5'-GCTAAGGAGTCCCTGGTTCA-3' } \\
\text { Reverse: 5'-ATTCACAAGAGTTGCGATTAGC-3' }\end{array}$ & 235 \\
\hline MAPKAPK3 & $\begin{array}{l}\text { Forward: 5'-AGCAGGATTCAGGAGCGTG-3' } \\
\text { Reverse: 5'-CCTTAGCAAAGCCAAAATCG-3' }\end{array}$ & 196 \\
\hline PDGFC & $\begin{array}{l}\text { Forward: 5'-TGTGGAAACTACCCTGCGATT-3' } \\
\text { Reverse: 5'-GCCCGAAGAGGCTCATTTG-3' }\end{array}$ & 165 \\
\hline PGF & $\begin{array}{l}\text { Forward: 5'-GCCCTGCTACCTGTTCTTGG-3' } \\
\text { Reverse: 5'-AAGCAAATGGCAAAGTGTGAG-3' }\end{array}$ & 266 \\
\hline SH2D2A & $\begin{array}{l}\text { Forward: 5'-AAGGCTGTGGGTAAGGCGA-3' } \\
\text { Reverse: 5'-GAAGGTGCTGAAGGTTGGGA-3' }\end{array}$ & 206 \\
\hline
\end{tabular}

rabbit anti-NR43A (ab92777; Abnova), anti-mouse HRP (Sigma) and anti-rabbit HRP (Sigma).

Cell proliferation assay. Four cell lines (MCF-7 NC, MCF-7 shSulf2, MDA-MB-231 vector and MDA-MB-231 Sulf2) were dissociated from cell flasks by trypsin (Sigma) digestion and seeded into 24 -well cell culture plates $\left(1 \times 10^{5}\right.$ cells/well). Cells were dissociated from wells with $0.25 \%$ trypsin and counted each day using a Bio-Rad cell counter (Bio-Rad Laboratories, Hercules, CA, USA). Cell growth curves were drawn from live cell numbers for seven days.

Apoptosis assay. Apoptosis was determined by dual staining using Annexin V:FITC and propidium iodide (Invitrogen). Briefly, log phase cells of these four cell lines were seeded into 24 -well cell culture plates $\left(1 \times 10^{5}\right.$ cells/well) and treated with $10 \mu \mathrm{g} / \mathrm{ml}$ cisplatin (Qilu Pharmaceutical Co., Shanghai, China) for $24 \mathrm{~h}$. Cells were dissociated from wells with $0.25 \%$ trypsin, spun at $1,500 \mathrm{rpm}$ for $5 \mathrm{~min}$, resuspended in Annexin V binding buffer, and stained with $1 \mu \mathrm{l}$ Annexin V:FITC for $15 \mathrm{~min}$ and $1 \mu \mathrm{l}$ propidium iodide for $1 \mathrm{~min}$. Cells were analyzed using the FACSCalibur System (BD Biosciences, San Jose, CA, USA). The relative proportion of Annexin V-positive cells, representing apoptotic cells, was determined using FlowJo software (FlowJo LLC, Ashland, OR, USA).
Cell cycle assay. The cell cycle was determined by propidium iodide staining and flow cytometric analysis. Log phase cells of these four cell lines were seeded and harvested as described above. They were then fixed in $70 \%$ ethanol overnight at $-20^{\circ} \mathrm{C}$ and incubated in RNase $\mathrm{A}$ at $37^{\circ} \mathrm{C}$ for $30 \mathrm{~min}$. Propidium iodide was added and cells were incubated in the dark for $30 \mathrm{~min}$. Flow cytometry was used to detect the cell cycle status. The proliferation index (PI) was calculated using the formula: $\mathrm{PI}=$ $(\mathrm{S}+\mathrm{G} 2) /(\mathrm{S}+\mathrm{G} 1+\mathrm{G} 2) \times 100 \%$.

Cell invasion assay. The migration of the four breast cancer cell lines was measured in 12-well Boyden chamber plates with $8 \mu \mathrm{m}$ pore size polycarbonate membrane filter inserts (CoStar Group, Inc., Washington, DC, USA). For the cell invasion assay, the interior of the Transwell insert was coated with diluted Matrigel (BD Biosciences), which imitates the basement membrane. A total of $1 \times 10^{5}$ cells were seeded onto the upper chamber, the cell suspension was also seeded onto the membrane in the upper chamber, and the lower chamber was filled with $1 \mathrm{ml} 10 \%$ FBS-DMEM. After being incubated for $48 \mathrm{~h}$, the non-migrating cells in the upper chamber surface were removed by cotton swabs. The migrating cells at the bottom of the membrane were fixed with formaldehyde for $1 \mathrm{~min}$ and stained with crystal violet. The stained membranes were cut and placed onto a glass slide, and the numbers of invading cells at the bottom 
surface of the membrane were counted three times under a bright field light microscope.

Cell mobility assay. Four breast cancer cell lines were cultured in 6-well plates and incubated until $90 \%$ confluent. A scratch was made using a sterile blade. Cell debris was then washed off, and the cells continued to be cultured in low FBS medium for $18 \mathrm{~h}$ for the MDA-MB-231 cells and $36 \mathrm{~h}$ for the MCF-7 cells. Then, the movement of the breast cancer cells into the scratch area was monitored under an inverted microscope to evaluate cell mobility in vitro.

Cell adhesion assay. Four breast cancer cell lines were cultured in 10\% FBS-DMEM and seeded into 96-well plates with $30 \mu \mathrm{l} /$ well collagen I solution at $4^{\circ} \mathrm{C}$ for $12 \mathrm{~h}$. After depriving cells of serum for $8 \mathrm{~h}$, cells were washed twice with DMEM and resuspended in DMEM with $0.1 \%$ BSA to $2 \times 10^{5}$ cells $/ \mathrm{ml}$. Next, $100 \mu \mathrm{l}$ cell suspension was added into each collagen I-coated well at $37^{\circ} \mathrm{C}$ for $20 \mathrm{~min}$. Non-adherent cells were washed off and incubated at $37^{\circ} \mathrm{C}$ for $4 \mathrm{~h}$. Then, $10 \mu \mathrm{l}$ MTT and $100 \mu \mathrm{l}$ DMSO were added into each well. After $2 \mathrm{~h}$ the absorbance value of each well was measured at $570 \mathrm{~nm}$ using a spectrophotometer.

Tumor metastasis and VEGF signaling PCR array assay. Total mRNA was isolated and reverse transcribed as above. Genetic screening was performed using the tumor metastasis PCR array and the Human VEGF Signaling PCR array (Qiagen, Hilden, Germany) in MCF-7 NC and MCF-7 shSulf2 cells following the manufacturer's instructions.

Mouse mammary pad injection. Six-week-old, 18-g female NOD/SCID mice were purchased from Shanghai Experimental Animal Center Chinese Academy of Sciences (Shanghai, China). Four cultured breast cancer cell lines were digested with $0.25 \%$ trypsin and resuspended in HBSS/Matrigel (1:1 volume) to $10^{7}$ cell $/ \mathrm{ml}$. Xenografts were generated by injecting $0.2 \mathrm{ml}$ cell suspension into the area of the mammary fat pad. Growth of the xenografts was measured every week, and the volumes of the xenografts were calculated using the formula: volume = length $\mathrm{x}$ width $\mathrm{x}$ height $\mathrm{x} \pi / 6$. All experimental protocols followed the instructions of the Chinese Council on Animal Care and were approved by the Animal Experimental Ethical Inspection of Shanghai Ninth People's Hospital affiliated to Shanghai Jiaotong University, School of Medicine [permit no. (20015) 25].

Xenograft invasion assay. Excised xenografts were fixed in formalin buffer and embedded in paraffin. Five micron sections from formalin-fixed, paraffin-embedded tissues were de-paraffinized with xylene and rehydrated through a graded alcohol series. Heat induced epitope retrieval (HIER) was performed by immersing the tissue sections at $98^{\circ} \mathrm{C}$ for $20 \mathrm{~min}$ in $8 \mathrm{mM}$ EDTA ( $\mathrm{pH}$ 8.0). Slides were counterstained with hematoxylin (Thermo Fisher Scientific, Waltham, MA, USA), in $1 \%$ ammonium hydroxide and dehydrated.

Statistical analysis. Data are presented as the mean \pm standard deviation (SD) of at least three independent experiments with three or more replicates. Continuous data were analyzed using a two-tailed Student's t-test. $\mathrm{P}<0.05$ was considered a significant difference.

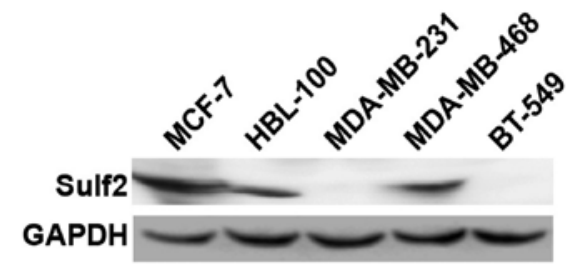

Figure 1. Sulf2 protein expression in different breast cancer cell lines and one mammary epithelial cell line. MCF-7, HBL-100 and MDA-MB-468 cell lines highly expressed endogenous Sulf2 protein, with MCF-7 cells had the highest expression. MDA-MB-231 and BT549 breast cancer cell lines did not express Sulf2 protein.

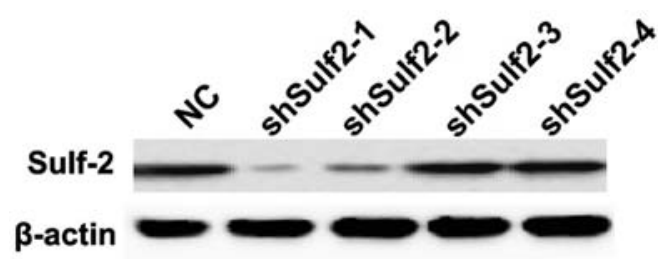

Figure 2. Screen of the silencing efficiency of shSulf2-1 to 4 vectors in MCF-7 cells by western blot analysis. MCF-7 cells were transfect with shSulf2-1 to 4 vectors, and Sulf 2 protein level were reduced by $86.23,79.79,28.66$ and $25.27 \%$, respectively.

\section{Results}

Sulf2 is differentially expressed in five cell lines. To select breast cancer cell lines with different Sulf2 expression levels for studying the biological function of Sulf2, endogenous Sulf2 protein was detected using western blot analysis in five cell lines: MCF-7, MDA-MB-468, HBL-100, MDA-MB-231 and BT-549. MCF-7, MDA-MB-468 and HBL-100 cells highly expressed Sulf2 protein. Conversely, MDA-MB-231 and BT-549 cells did not express Sulf2 protein (Fig. 1). The MCF-7 and MDA-MB-231 breast cancer cell lines therefore were selected to ascertain the role of Sulf 2 in breast cancer.

Silencing efficiency of Sulf2 shRNA vectors screened in $M C F-7$. To examine the efficiency of silencing constructs shSulf2-1 to shSulf2-4, MCF-7 cells were transfected with these constructs, and the Sulf2 protein levels were detected by western blot analysis. Compared with the negative control (NC) transfect with a blank vector, the Sulf2 protein expression was downregulated in the MCF-7 shSulf2-1, shSulf2-2, shSulf2-3 and shSulf2-4 groups by $86.23,25.27,28.66$ and $79.79 \%$ respectively (Fig. 2). Therefore, shSulf2-1 was selected to perform the Sulf2 silencing study.

Sulf2 expression is altered in breast cancer cell lines. The Sulf2 mRNA levels in MCF-7 NC, MCF-7 shSulf2, MDA-MB-231 vector and MDA-MB-231 Sulf2 cells were determined by qRT-PCR. The Sulf2 mRNA level in MCF-7 shSulf2 cells was reduced $98 \%$ compared with MCF-7 NC cells (0.02 \pm 0.045 vs. $1.00, \mathrm{P}<0.01$; Fig. 3A). Conversely, the Sulf 2 mRNA levels in MDA-MB-231 Sulf2 cells increased significantly compared with MDA-MB-231 vector cells $(38,906.96 \pm 0.061$ vs. 1.00 , $\mathrm{P}<0.01$; Fig. 3B). Moreover, the Sulf 2 expression in MDA-MB231 Sulf 2 cells was 16 -fold higher than that in MCF-7 NC cells 
A

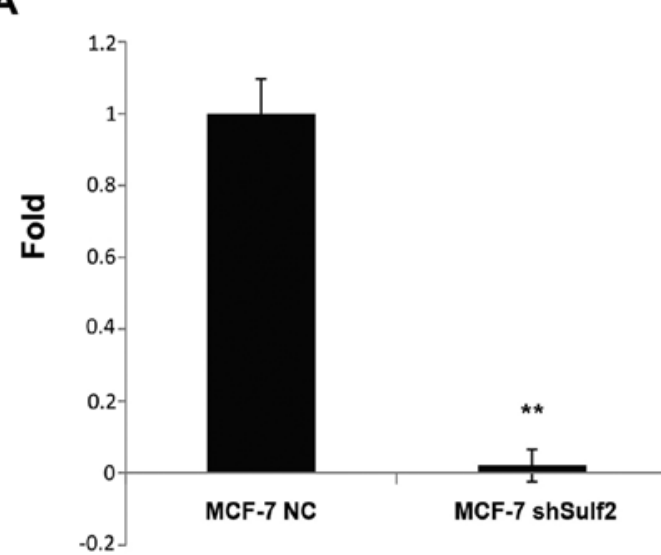

C

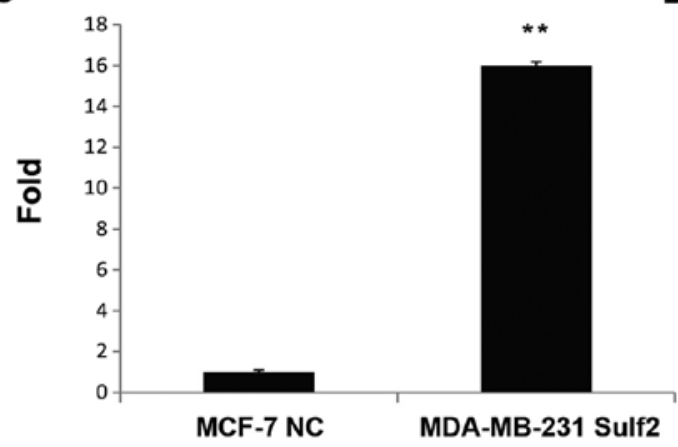

B

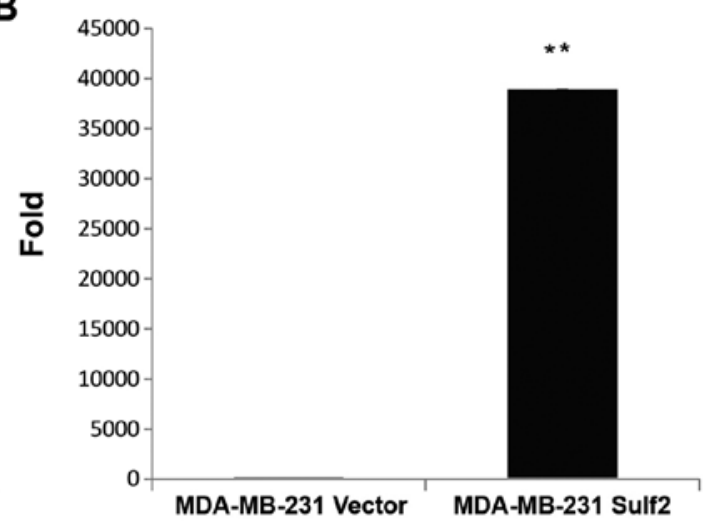

Figure 3. Sulf2 expression is altered in MCF-7 and MDA-MB-231 breast cancer cell lines. (A) The mRNA level of Sulf2 in MCF-7 shSulf2 was significantly lower than in MCF-7 NC. (B) The mRNA level of Sulf2 in MDA-MB-231 Sulf2 was significantly higher than in MDA-MB-231 vector. (C) The mRNA level of Sulf2 in MDA-MB-231 Sulf2 was 16-fold higher than in MCF-7 NC. (D) Sulf2 protein levels detected by western blot analyis were consistent with qRT-PCR results. ${ }^{*} \mathrm{P}<0.05,{ }^{* *} \mathrm{P}<0.01$.

A

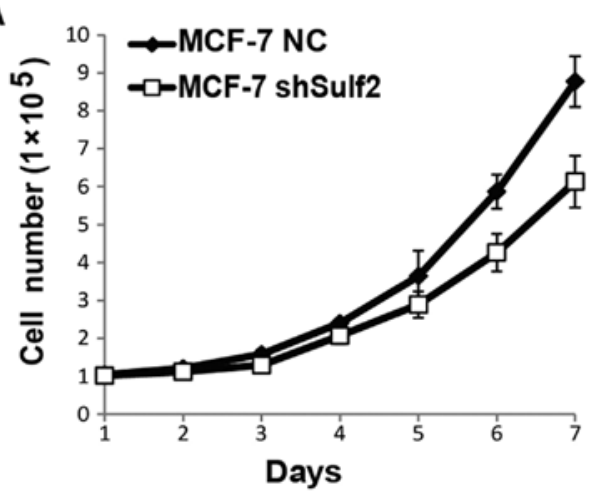

B

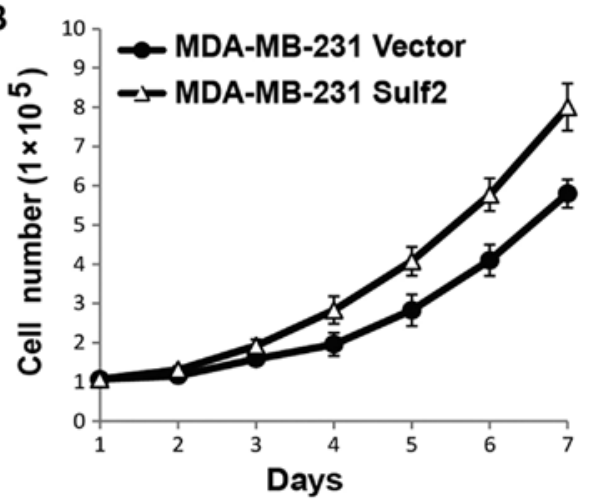

Figure 4. The cell proliferation growth curves of four breast cancer cell lines. (A) MCF-7 NC cells showed consistently higher growth rates than MCF-7 shSulf2. The difference was significant after the sixth day $(\mathrm{P}<0.05)$. (B) MDA-MB-231 Sulf2 cells also showed a significantly increased growth rate compared to MDA-MB-231 vector cells after the fourth day $(\mathrm{P}<0.05)$.

(16.90 \pm 0.061 vs. $1.00, \mathrm{P}<0.01$; Fig. $3 \mathrm{C})$. These data reflected significant differences in Sulf2 mRNA levels in different breast cancer cell lines. The changes in Sulf2 protein levels in these four cell lines were also confirmed by western blot analysis (Fig. 3D).

Sulf 2 promotes cell proliferation. To evaluate the effects of Sulf2 on breast cancer proliferation, cell numbers were counted every day for seven days using the four cell lines above, and live cell numbers were used for cell growth curves. The Sulf2 knockdown MCF-7 shSulf2 cells showed a consistently lower growth rate than MCF-7 NC. The difference was significant after the sixth day (P<0.05; Fig. 4A). Similarly, MDA-MB-231 Sulf 2 also showed a significantly higher growth rate than MDA-MB-231 vector. The difference was significant after the fourth day $(\mathrm{P}<0.05$; Fig. 4B). Collectively, these data indicated that Sulf2 promoted breast cancer proliferation.

Sulf2 inhibits breast cancer apoptosis. Previous studies show that the MCF-7 breast cancer cell line is not sensitive to 
A
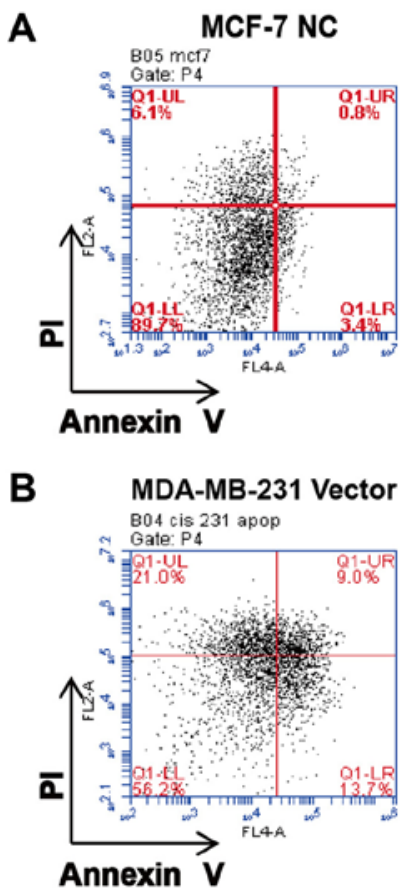
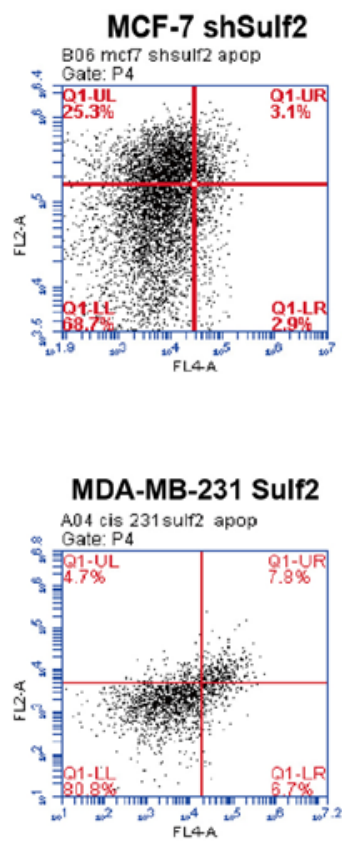

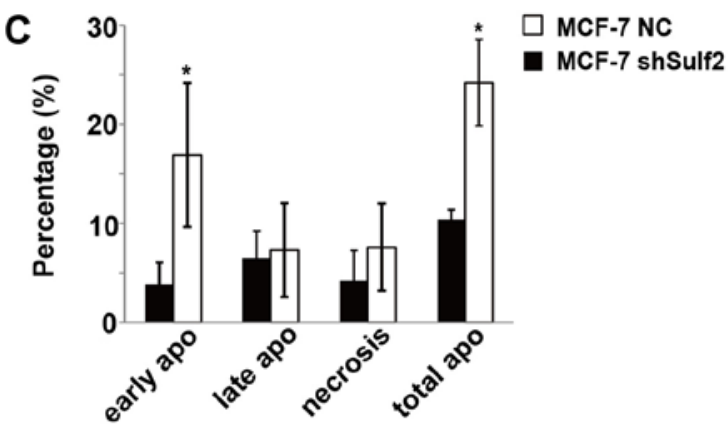

D

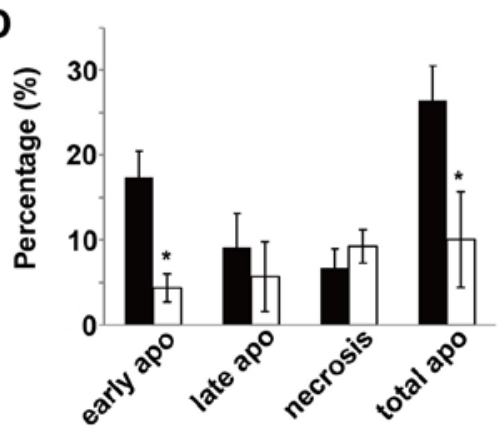

MDA-MB-231 Vector MDA-MB-231 Sulf2

Figure 5. Sulf2 expression inhibits breast cancer apoptosis. (A) Annexin V/propidium iodide labeled apoptotic MCF-7 NC and MCF-7 shSulf2 cells was detected using flow cytometry. (B) Annexin V/propidium iodide labeled apoptotic MDA-MB-231 vector and MDA-MB-231 Sulf2 cells were detected using flow cytometry. (C) Silencing of Sulf2 promoted MCF-7 shSulf2 apoptosis. (D) Sulf2 overexpression blocked MDA-MB-231 Sulf2 apoptosis. ${ }^{*} \mathrm{P}<0.05$, ${ }^{* *} \mathrm{P}<0.01$.

cisplatin-based chemotherapy and can resist cisplatin induced cell apoptosis and necrosis (data not shown). Conversely, the MDA-MB-231 breast cancer cell line is more sensitive to cisplatin-based chemotherapy and cisplatin induced MDA-MB-231 cell apoptosis and necrosis. Compared with MCF-7 NC, the MCF-7 shSulf2 cell line had a significantly decreased live cell percentage $(68.2 \pm 4.76$ vs. $85.4 \pm 3.89, \mathrm{P}<0.05)$ and significantly increased total apoptosis $(24.19 \pm 4.35$ vs. $10.39 \pm 0.99, \mathrm{P}<0.05)$. A closer look at the different stages of apoptosis showed that the most significant difference between these two cell lines occurred in early apoptosis $(16.89 \pm 7.28$ vs. $3.88 \pm 2.16, \mathrm{P}<0.05$; Fig. 5). Moreover, compared with MDA-MB-231 Sulf2, the MDA-MB-231 Sulf2 cell line showed a significant increase in the live cell percentage $(85.4 \pm 5.51$ vs. $66.83 \pm 9.23, \mathrm{P}<0.05)$ and a significant decrease in total apoptosis $(8.83 \pm 2.47 \mathrm{vs}$. $26.44 \pm 7.17, \mathrm{P}<0.05)$, which was stronger in the early stage of apoptosis (4.27 \pm 0.64 vs. 17.31 \pm 3.19 , P<0.05; Fig. 5). Our studies showed that Sulf2 expression in breast cancer inhibited cisplatin-based breast cancer cells apoptosis, especially at early stage.

Sulf2 has no significant effect on the cell cycle in breast cancer with cisplatin pre-treatment. Compared with MCF-7 NC, MCF-7 shSulf2 did not show significant difference in G1 phase $(41.79 \pm 13.87$ vs. $42.51 \pm 14.84, \mathrm{P}>0.05), \mathrm{S}$ phase $(31.56 \pm 22.14$ vs. $27.19 \pm 11.31, \mathrm{P}<0.05)$, and $\mathrm{G} 2 / \mathrm{M}$ phase $(25.43 \pm 9.85$ vs. $29.28 \pm 2.09, \mathrm{P}>0.05)$. The PI index $(0.58 \pm 0.13$ vs. $0.57 \pm 0.14$, $\mathrm{P}>0.05$ ) also had no difference between these cells (Fig. 6A and C). Similarly, MDA-MB-231 Sulf2 did not show significant difference in G1 phase $(42.95 \pm 18.25$ vs. $35.98 \pm 1.10$, $\mathrm{P}>0.05), \mathrm{S}$ phase $(32.54 \pm 6.41$ vs. $29.69 \pm 4.51, \mathrm{P}>0.05), \mathrm{G} 2 / \mathrm{M}$ phase $(30.53 \pm 2.58$ vs. $38.46 \pm 0.46, \mathrm{P}>0.05)$, and the PI index
$(60.34 \pm 0.14$ vs. $65.69 \% \pm 0.08, \mathrm{P}>0.05)$ (Fig. $6 \mathrm{~B}$ and $\mathrm{D})$ when compared with MDA-MB-231 vector. These data indicated that Sulf2 expression differences had no significant effect on the cell cycles in breast cancer cell lines with cisplatin pretreatment in vitro.

Sulf2 enhances breast cancer invasion. Sulf 2 expression was also positively associated with higher invasion in Transwell chamber assay. Compared with MCF-7 NC, the downregulation of Sulf2 in the MCF-7 shSulf2 cell line significantly reduced the average number of cells that migrated though the chamber

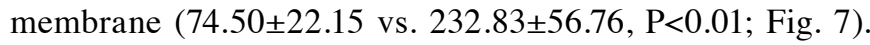
The opposite observation was made when the overexpression of Sulf2 in MDA-MB-231 Sulf2 caused a significant increase $(517.50 \pm 77.02$ vs. $179.67 \pm 44.81, \mathrm{P}<0.01$; Fig. 7$)$ in the number of cells that migrated to the lower chamber, compared with MDA-MB-231 vector. These observations clearly suggested that Sulf2 expression improved breast cancer invasion.

Sulf2 promotes breast cancer migration. Higher Sulf2 expression was positively associated with cell migration, as demonstrated by scratch wound healing assays using the same four cell lines. Compared with MCF-7 NC, the MCF-7 shSulf2 cell line showed markedly slower healing of the scratch after $36 \mathrm{~h}$ (Fig. 8). Overexpression of Sulf2 in the MDA-MB-231 Sulf 2 cell line markedly increased the scratch wound healing ability (Fig. 8) compared with MDA-MB-231 vector at $18 \mathrm{~h}$. These observations suggested that Sulf 2 expression was associated with breast cancer cell migration.

Sulf2 improves breast cancer adhesion. Compared with MCF-7 NC, the absorbance value in MCF-7 shSulf2 was 
A

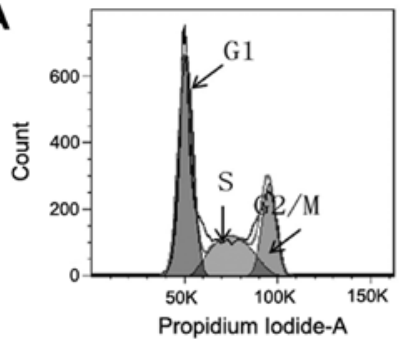

B

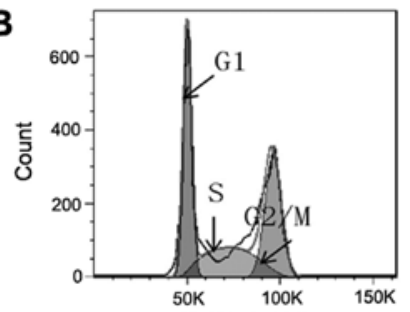

Propidium lodide-A

C

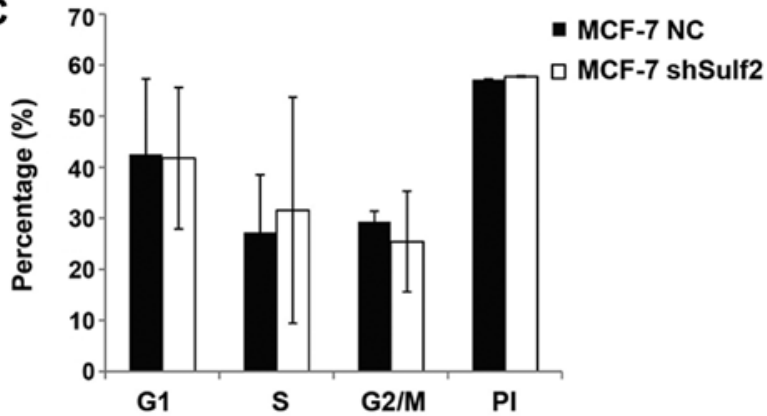

D

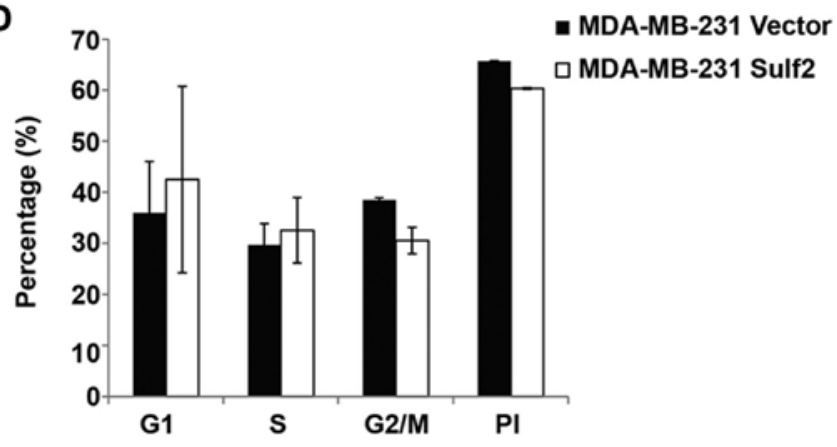

Figure 6. Sulf2 had no effect on the cell cycle in breast cancer with cisplatin pre-treatment. (A) Cell cycle in MCF-7 NC and MCF-7 shSulf2 was detected using flow cytometry, and the abscissa indicates the amount of DNA. G1, S and $\mathrm{G} 2$ /M phases are marked. (B) Cell cycle in MDA-MB-231 vector and MDA-MB-231 Sulf2 was detected using flow cytometry, and the abscissa indicates the amount of DNA. G1, S and G2 /M phases are marked. (C) Graph demonstrates the effects of Sulf2 silencing on the cell cycle of MCF-7. (D) Graph demonstrates the effects of Sulf 2 overexpression on the cell cycles of MDA-MB-231. ${ }^{*} \mathrm{P}<0.05,{ }^{* *} \mathrm{P}<0.01$.

significantly reduced $(0.17 \pm 0.02$ vs. $0.21 \pm 0.02, \mathrm{P}<0.05)$. This result suggested that Sulf2 silencing reduced the adhesion of breast cancer cells with the extracellular matrix. Compared with MDA-MB-231 vector, MDA-MB-231 Sulf2 cells cultured in a fibronectin (FN)-coated 96-well plate showed increased cell adhesion. The absorbance value in MDA-MB-231 Sulf2 cells was significantly higher than that in MDA-MB-231 vector cells $(0.40 \pm 0.13$ vs. $0.25 \pm 0.02, \mathrm{P}<0.05)$, indicating that Sulf2 was associated with breast cancer adhesion in vitro (Fig. 9).
A
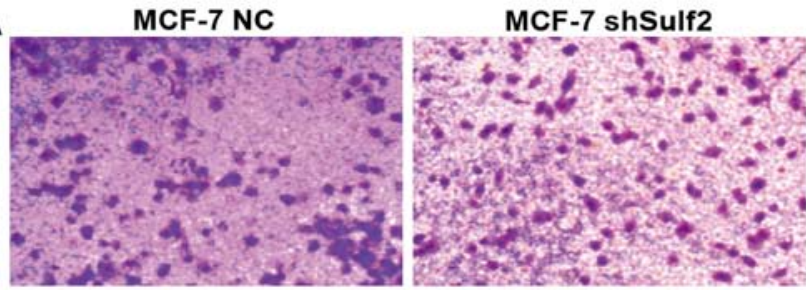

B

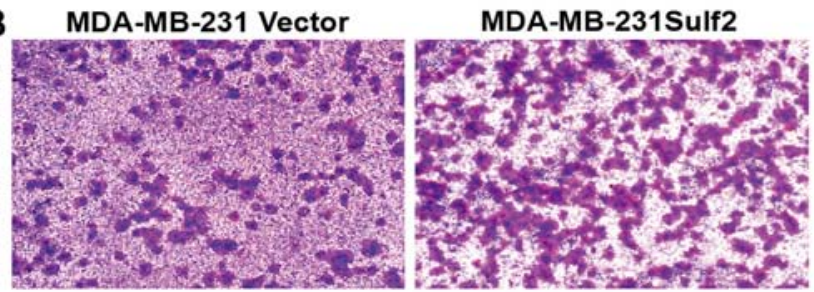

Co

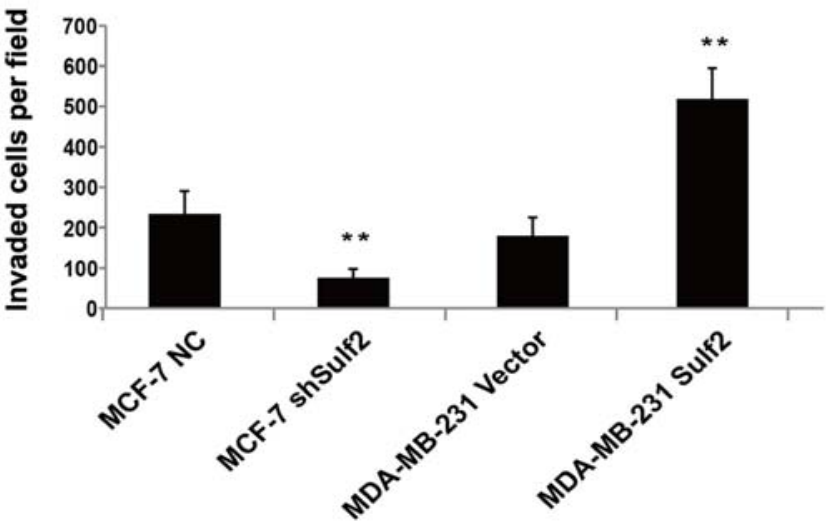

Figure 7. Sulf 2 expression increases breast cancer cell migration through Matrigel and fibronectin. (A) The number of MCF-7 shSulf2 cells migrated though the membrane was significantly lower than that of MCF-7 NC. (B) The number of MDA-MB-231 Sulf2 cells through the chamber membrane was significantly more than that of MDA-MB-231 vector. (C) Graphs showed the numbers of cells migrated through membranes for four cell lines. ${ }^{*} \mathrm{P}<0.05,{ }^{* *} \mathrm{P}<0.01$.

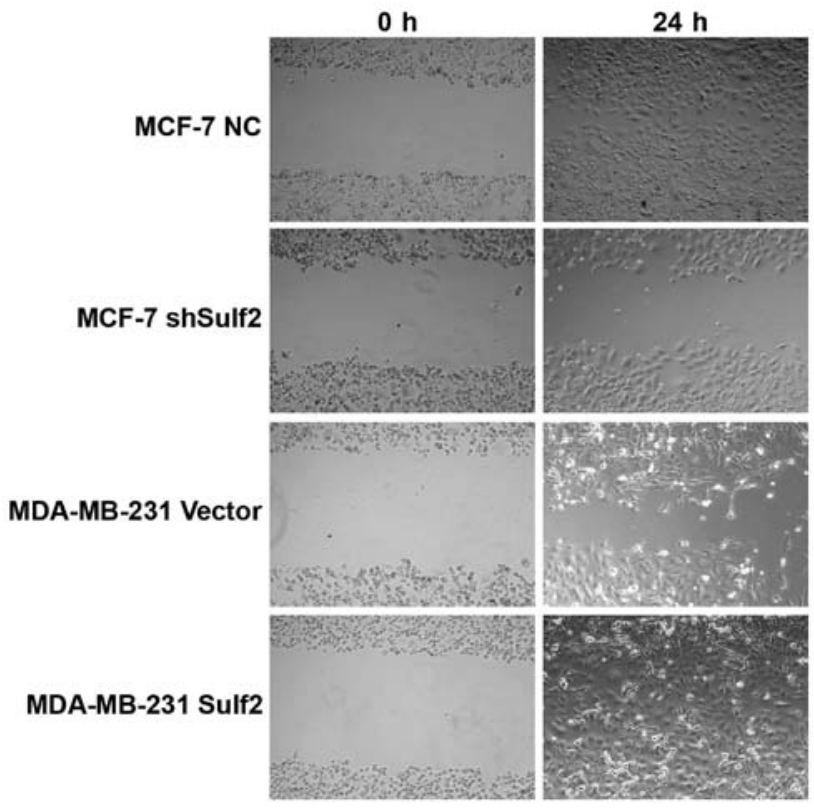

Figure 8. Sulf2 expression promotes breast cancer cell mobility. Compared with MCF-7 NC, fewer MCF-7 shSulf2 cells migrated into the scratch after 36 h. Conversely, more MDA-MB-231 Sulf2 cells migrated into the scratch area after $18 \mathrm{~h}$ compared with MDA-MB-231 vector cells. 


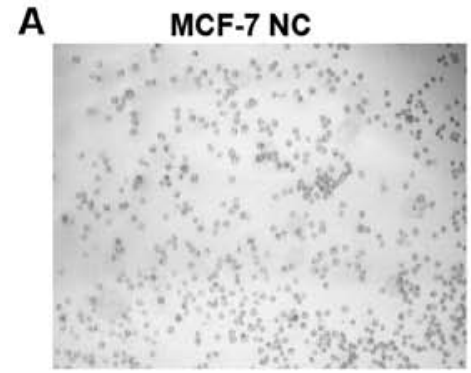

B

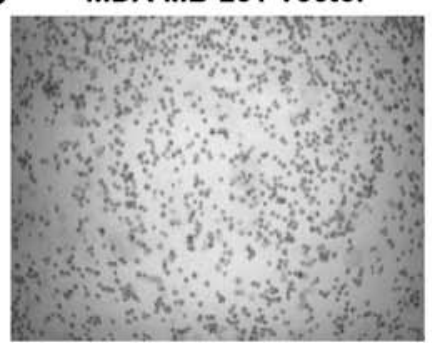

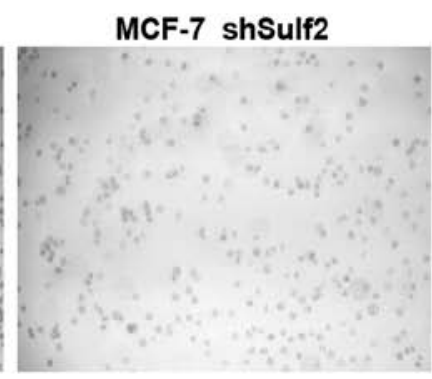

MDA-MB-231 Sulf2

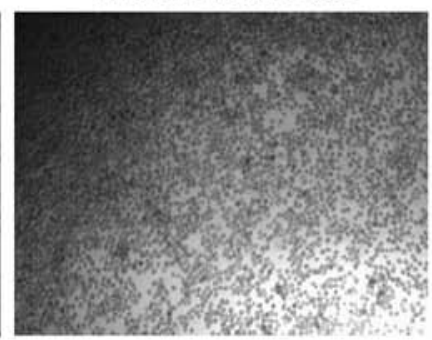

C

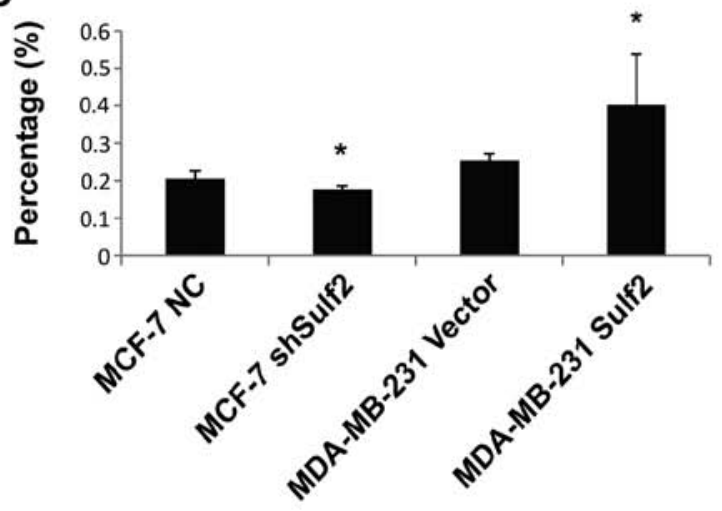

Figure 9. Sulf2 expression increased breast cancer adhesion in vitro. (A) The MCF-7 shSulf2 cells showed significantly lower adhesion than MCF-7 NC cells. (B) MDA-MB-231 Sulf2 cell had significantly better adhesion than MDA-MB-231 vector cells. (C) Comparison of MTT values showed significant difference between cell lines. ${ }^{*} \mathrm{P}<0.05,{ }^{* * *} \mathrm{P}<0.01$.

A

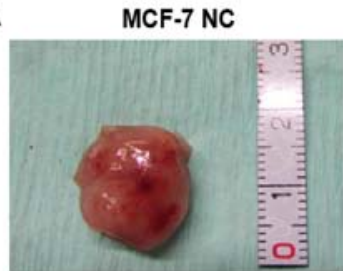

MDA-MB-231 Vector

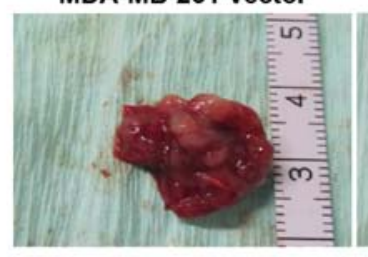

B

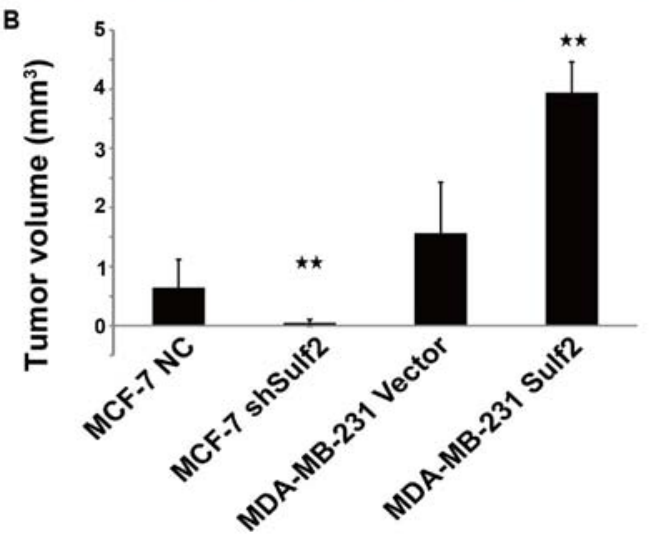

MCF-7 shSulf2

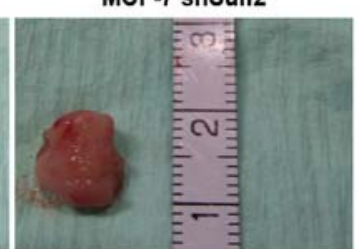

MDA-MB-231 Sulf2
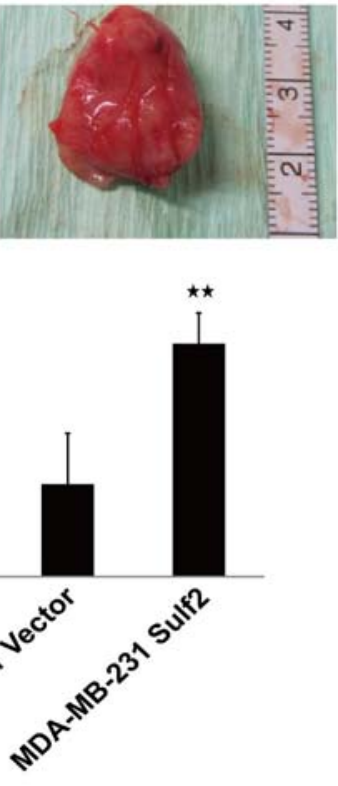

Figure 10. Sulf2 promotes tumorigenicity of breast cancer cells in vivo. (A) Xenografts formed in SCID mice. (B) Breast cancer xenograft volumes were compared among four breast cancer groups. ${ }^{*} \mathrm{P}<0.05,{ }^{* *} \mathrm{P}<0.01$.

Sulf2 promotes tumorigenicity of breast cancer cells in vivo. To determine whether the Sulf 2 expression level affects tumorigenicity of breast cancer cells in vivo, we injected the four cell lines into the mammary pads of nude mice and began measurement of tumor formation from day 7 . There was no significant difference in the time required for tumor formation between MDA-MB-231 Sulf2 and MDA-MB-231 vector $(7.17 \pm 0.98$ vs. $6.83 \pm 0.41, \mathrm{P}>0.05)$. However, MCF-7 shSulf2 formed tumor later than MCF-7 NC $(12.38 \pm 1.52$ vs. $7.17 \pm 0.98, \mathrm{P}<0.05$ ). After 35 days, $100 \%$ (6 out of 6 ) of the nude mice injected with MCF-7 NC, MDA-MB-231 vector, and MDA-MB-231 Sulf2 developed tumors, while 50\% (3 out of 6) $(\mathrm{P}<0.05)$ of the nude mice injected with MCF-7 shSulf2 formed tumors. The sizes of these tumors were measured and calculated every week. The tumors derived from MCF-7 shSulf2 and MDA-MB-231 vector were significantly smaller than those from MCF-7 NC and MDA-MB-231 Sulf2, respectively. Xenografts were measured each week using a Vernier caliper, and the length and the width were recorded to evaluate the effect of Sulf2 on xenograft growth. Compared with MCF-7 $\mathrm{NC}$, the volume of MCF-7 shSulf2 tumors was significantly smaller $(0.05 \pm 0.05$ vs. $0.64 \pm 0.48, \mathrm{P}<0.05)$, which suggested that Sulf2 downregulated MCF-7 proliferation. Conversely, the MDA-MB-231 Sulf2 tumor volume was significantly larger than that of the MDA-MB-231 vector tumor $(3.94 \pm 0.51$ vs. $1.56 \pm 0.86, \mathrm{P}<0.05)$. These data suggested that Sulf 2 promoted breast cancer xenograft growth (Fig. 10).

Sulf 2 promotes breast cancer invasion in vivo. The xenografts were examined by pathological sections. The MDA-MB-231 Sulf2 tumor cells invaded the surrounding muscle tissue, showing significant infiltration and invasion ability. Their boundary was unclear, suggesting that Sulf 2 can promote breast cancer invasion and increase the malignancy of breast cancer. The MCF-7 shSulf2 xenografts showed membrane structures and no invasion. MCF-7 xenografts formed a capsule-like structure within the surrounding muscle tissue. The boundary line between the tumor and surrounding tissue was clear and showed fewer infiltrating tumor cells (Fig. 11). 
A

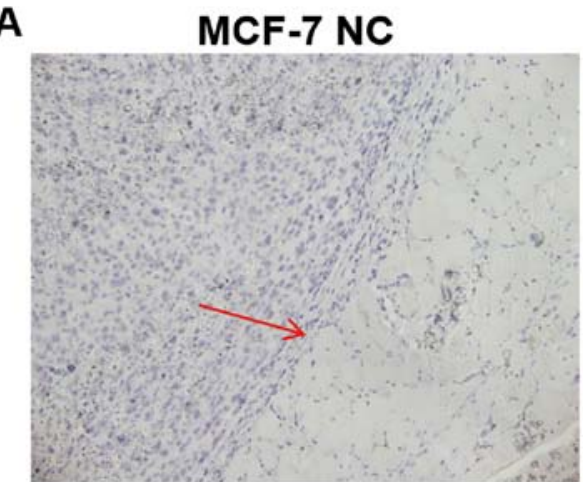

B

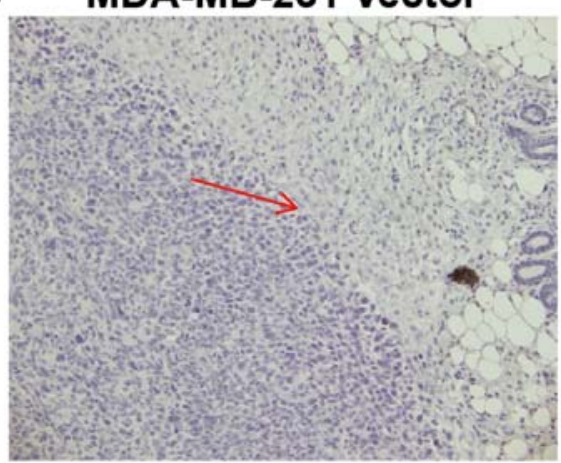

MCF-7 shSulf2

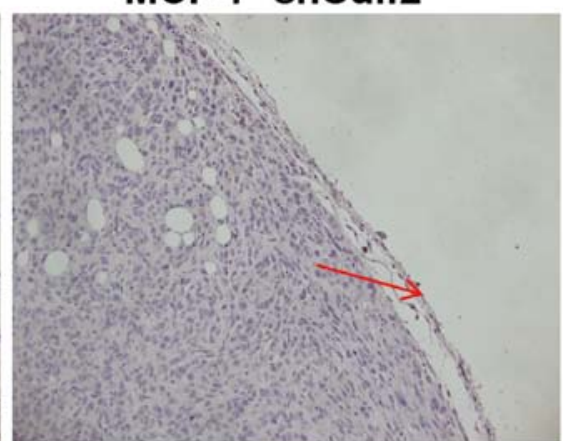

MDA-MB-231 Sulf2

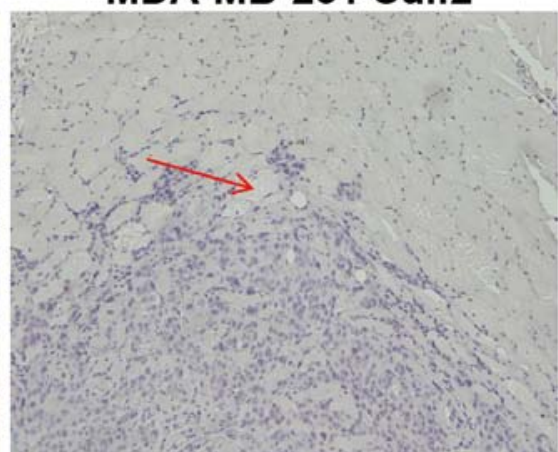

Figure 11. Sulf2 expression increases breast cancer xenograft invasion in vivo. (A) The xenograft of MDA-MB-231 Sulf2 tumor showed tumor cells clearly invaded the surrounding muscle tissue. (B) The MCF-7 shSulf2 xenografts showed some membrane structures with no significant invasion. MCF-7 NC xenografts had a capsule-like structure in the surrounding muscle tissue.

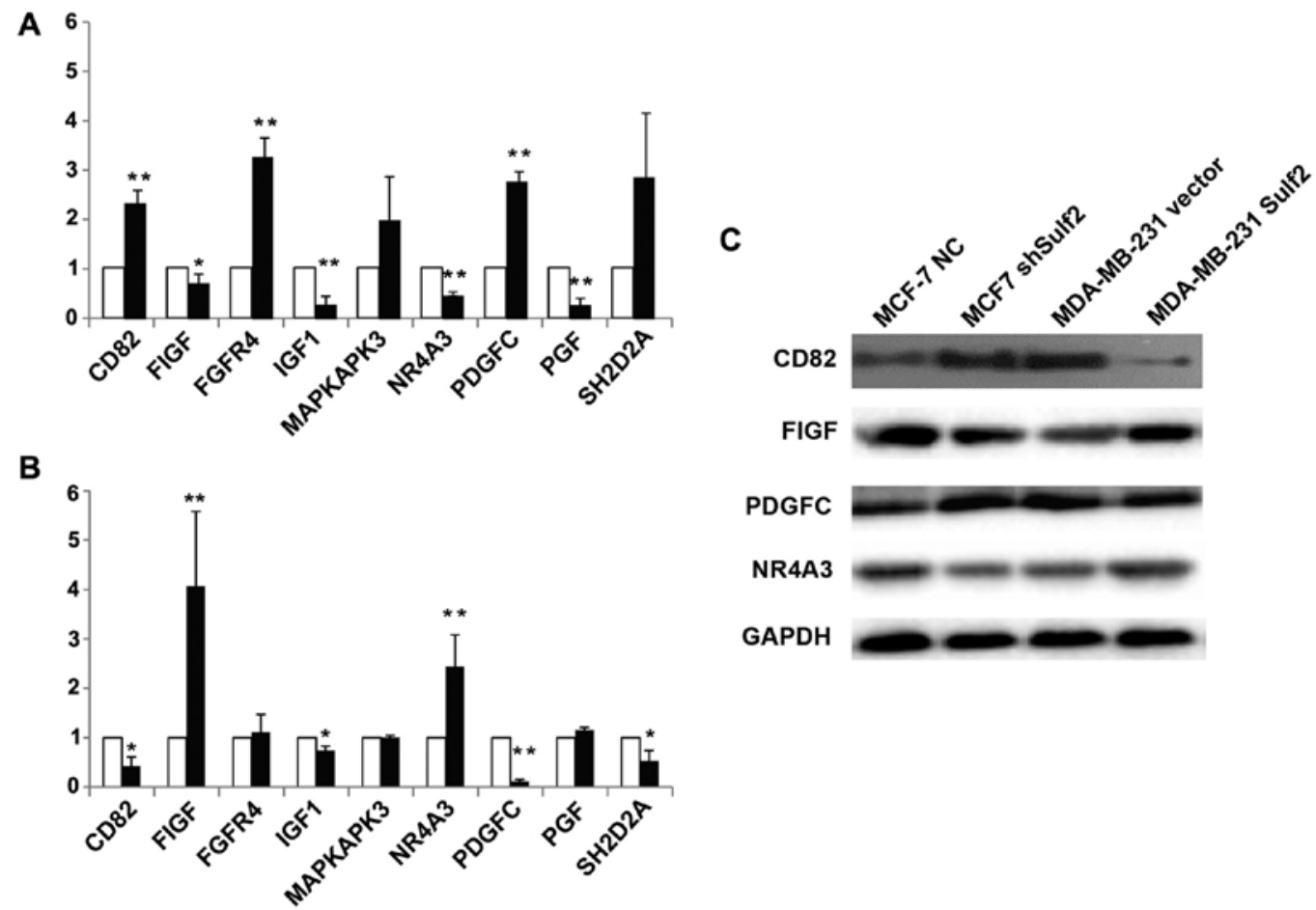

Figure 12. The results of the PCR microarray screening confirmed using real-time PCR. (A) The results of the PCR microarray screening were verified using qRT-PCR in MCF-7 NC and MCF-7 shSulf2 cell lines. (B) The results of the PCR microarray screening were confirmed using qRT-PCR in MDAMB-231 vector and MDA-MB-231 Sulf2 cells. (C) The Sulf2 protein expression of four genes were changed with alteration of Sulf 2 expression. ${ }^{*} \mathrm{P}<0.05$, ${ }^{* * *} \mathrm{P}<0.01$.

Sulf2 regulates growth factor expression in breast cancer. Messenger RNA levels of a panel of tumor metastasis and
VEGF signaling genes were first analyzed by PCR microarray followed by qRT-PCR and western blot verification. Compared 
with MCF-7 NC, the genes significantly upregulated in MCF-7 shSulf 2 were CD82 (2.18 \pm 0.21 vs. $1.00, \mathrm{P}<0.01)$, FGFR $(3.05 \pm 0.33$ vs. $1.00, \mathrm{P}<0.01)$ and PDGFC $(2.58 \pm 0.16$ vs. 1.00 , $\mathrm{P}<0.01)$. The genes significantly downregulated were FIGF $(0.67 \pm 0.14$ vs. $1.00, \mathrm{P}<0.05)$, IGF1 $(0.27 \pm 0.12$ vs. $1.00, \mathrm{P}<0.01)$, NR4A3 $(0.44 \pm 0.04$ vs. $1.00, \mathrm{P}<0.01)$ and PGF $(0.26 \pm 0.1$ vs. $1.00, \mathrm{P}<0.01)$ (Fig. 12A). Compared with MDA-MB231 vector, FIGF $(4.07 \pm 1.51$ vs. $1.00, \mathrm{P}<0.01)$ and NR4A3 $(2.44 \pm 0.64$ vs. $1.00, \mathrm{P}<0.01)$ were significantly upregulated in MDA-MB-231 Sulf2, while CD82 (0.42 \pm 0.19 vs. $1.00, \mathrm{P}<0.01)$, IGF1 $(0.74 \pm 0.09$ vs. $1.00, \mathrm{P}<0.05)$, PDGFC $(0.11 \pm 0.04$ vs $1.00, \mathrm{P}<0.01)$ and SH2D2A $(0.53 \pm 0.21$ vs. $1.00, \mathrm{P}<0.05)$ were significantly downregulated (Fig. 12A). Four genes (CD82, FIGF, NR4A3 and PDGFC) that showed significant changes in mRNA level in response to altered Sulf2 expression were chosen for western blot verification. CD82 and PDGFC protein expression were negatively correlated with Sulf 2 expression, but FIGF and NR4A3 protein expression were positively correlated with Sulf 2 expression. Sulf 2 may be the upstream gene regulating these four genes.

\section{Discussion}

Sulf2 has been reported as an important mediator of carcinogenesis in many cancer types. However, its role in breast cancer was inconsistent in different reports, making it necessary to clearly define the effects of Sulf2 in specific cancers, especially breast cancer (19). Morimoto et al (15) reported that Sulf 2 mRNA was upregulated in two mouse models of mammary carcinoma compared with its expression in the normal mammary gland. Although the mRNA was present in normal tissues, Sulf2 protein was undetectable. However, Sulf2 can be detected in some premalignant lesions and in tumors. Khurana et al (20) found that Sulf2 silencing promoted matrix detachment, induced MCF10DCIS cell death, promoted apoptosis and maintained the acne-like structure. In their later study, the Sulf2 specific inhibitor Bortezomib significantly reduced tumor size, caused massive apoptosis and, more importantly, reduced Sulf2 levels in vivo.

In the present study, we used two human breast cancer cell lines, MCF-7 and MDA-MB-231, that respectively expresses Sulf 2 and lacks Sulf 2 expression. We altered the Sulf 2 expression in these two cell lines by knocking down or overexpressing Sulf2 using shRNA and overexpression constructs to study the biological effects of Sulf2 in breast cancer. We found that Sulf2 silencing in MCF-7 cells significantly decreased cell proliferation, invasion, mobility and adhesion, and increased cisplatin-induced cell apoptosis, especially in early stage apoptosis. Conversely, Sulf2 overexpression in MDA-MB-231 increased cell proliferation and decreased cisplatin-induced cell apoptosis and necrosis. Our experiments suggested that Sulf2 was positively related to the apoptosis of breast cancer cells, and Sulf 2 may be a molecular target for breast cancer drug resistance. In the present study, Sulf 2 has no effect on breast cancer cell cycle after cisplatin pre-treatment. We speculated that Sulf 2 could not completely salvage the cells from the damage caused by cisplatin possibly because cisplatin is a non-specific platinum-containing antitumor drug that could block cell cycles in all breast cancer cells. Our data indicated that Sulf 2 could influence the cell cycle status of breast cancer without cisplatin- treatment which improved cell proliferation in vitro and in vivo. Further study is needed to verify this hypothesis.

Invasion of tumor cells of the surrounding tissue and the distant metastasis are complicated procedures which involve many mechanisms $(21,22)$, including matrix metalloproteinases, adhesion molecules and growth factors. Many of these factors are regulated by HSPGs, such as growth factors, cytokines, chemotactic factors, proteases, lipases, lipoproteins, matrix proteins and cell adhesion molecules (23-25). Sulf 2 can affect a large number of protein ligands and their molecular biological activity by removing the HSPG sulfate amino glucose sulfuric acid. Sulf 2 can therefore regulate these factors by forming a common receptor with HSPGs $(19,26)$.

In this study, we assessed the effects of Sulf 2 on breast cancer cell extracellular matrix adhesion, cell migration, motility and invasion using a series of assays, including adhesion assay, scratch assay and Transwell chamber assay. Our results showed that invasion, mobility and adhesion were decreased when Sulf2 was inhibited in MCF-7 cells, and we observed converse results when Sulf2 was overexpressed in MDA-MB-231 cells.

Sulf2 increased breast cancer cell proliferation, invasion and metastasis and decreased apoptosis in the present study. To further evaluate the mechanism of action of Sulf2 in breast cancer metastasis using the tumor metastasis PCR array. Furthermore, because Sulf2 is closely related to angiogenesis, we used the VEGF signal PCR array to screen its signaling pathways. All results were confirmed by qRT-PCR and western blot analysis. Sulf2 increased FIGF and NR4A3 expression and inhibited CD82 and PDGFC expression. FIGF is also known as vascular endothelial growth factor (VEGF-D) and is a member of the VEGF family. VEGF-D is a ligand of the vascular endothelial growth factor receptors (VEGFRs) which can activate the subsequent signaling pathways and active angiogenesis, lymphangiogenesis and endothelial cell growth and migration (26). Our previous studies showed that VEGF-D was significantly elevated in the clinical specimens of patients with lymph node-positive breast cancer and closely related to the density of lymphatic vessels around the tumor (27). In this study, we found that the expression of VEGF-D in breast cancer cells decreased after Sulf2 inhibition in MCF-7 and increase in MDA-MB-231 after Sulf2 overexpression, suggesting that Sulf2 was positively correlated to VEGF-D expression. Our next aim is to understand the role of Sulf 2 in the lymphangiogenesis of breast cancer.

\section{References}

1. Joy AA, Ghosh M, Fernandes R and Clemons MJ: Systemic treatment approaches in her2-negative advanced breast cancerguidance on the guidelines. Curr Oncol 22 (Suppl 1): S29-S42, 2015.

2. Fina E, Callari M, Reduzzi C, D'Aiuto F, Mariani G, Generali D, Pierotti MA, Daidone MG and Cappelletti V: Gene expression profiling of circulating tumor cells in breast cancer. Clin Chem 61: 278-289, 2015.

3. Bishop JR, Schuksz M and Esko JD: Heparan sulphate proteoglycans fine-tune mammalian physiology. Nature 446: 1030-1037, 2007.

4. Turnbull J, Powell A and Guimond S: Heparan sulfate: Decoding a dynamic multifunctional cell regulator. Trends Cell Biol 11: 75-82, 2001.

5. Rosen SD and Lemjabbar-Alaoui H: Sulf-2: An extracellular modulator of cell signaling and a cancer target candidate. Expert Opin Ther Targets 14: 935-949, 2010. 
6. Maltseva I, Chan M, Kalus I, Dierks T and Rosen SD: The SULFs, extracellular sulfatases for heparan sulfate, promote the migration of corneal epithelial cells during wound repair. PLoS One 8: e69642, 2013.

7. Fujita K, Takechi E, Sakamoto N, Sumiyoshi N, Izumi S, Miyamoto T, Matsuura S, Tsurugaya T, Akasaka K and Yamamoto T: HpSulf, a heparan sulfate 6-O-endosulfatase, is involved in the regulation of VEGF signaling during sea urchin development. Mech Dev 127: 235-245, 2010.

8. Uchimura K, Morimoto-Tomita M, Bistrup A, Li J, Lyon M, Gallagher J, Werb Z and Rosen SD: HSulf-2, an extracellular endoglucosamine-6-sulfatase, selectively mobilizes heparinbound growth factors and chemokines: Effects on VEGF, FGF-1, and SDF-1. BMC Biochem 7: 2, 2006.

9. Khurana A, Jung-Beom D, He X, Kim SH, Busby RC, Lorenzon L, Villa M, Baldi A, Molina J, Goetz MP, et al: Matrix detachment and proteasomal inhibitors diminish Sulf2 expression in breast cancer cell lines and mouse xenografts. Clin Exp Metastasis 30: 407-415, 2013

10. Hammond E, Khurana A, Shridhar V and Dredge K: The role of heparanase and sulfatases in the modification of heparan sulfate proteoglycans within the tumor microenvironment and opportunities for novel cancer therapeutics. Front Oncol 4: 195, 2014.

11. Khurana A, Liu P, Mellone P, Lorenzon L, Vincenzi B, Datta K Yang B, Linhardt RJ, Lingle W, Chien J, et al: HSulf-1 modulates FGF2- and hypoxia-mediated migration and invasion of breast cancer cells. Cancer Res 71: 2152-2161, 2011.

12. Peterson SM, Iskenderian A, Cook L, Romashko A, Tobin K Jones M, Norton A, Gómez-Yafal A, Heartlein MW, Concino MF, et al: Human sulfatase 2 inhibits in vivo tumor growth of MDA-MB-231 human breast cancer xenografts. BMC Cancer 10: 427, 2010.

13. Lai JP, Sandhu DS, Yu C, Han T, Moser CD, Jackson KK, Guerrero RB, Aderca I, Isomoto $\mathrm{H}$, Garrity-Park MM, et al: Sulfatase 2 up-regulates glypican 3, promotes fibroblast growth factor signaling, and decreases survival in hepatocellular carcinoma. Hepatology 47: 1211-1222, 2008.

14. Nawroth R, van Zante A, Cervantes S, McManus M, Hebrok M and Rosen SD: Extracellular sulfatases, elements of the Wnt signaling pathway, positively regulate growth and tumorigenicity of human pancreatic cancer cells. PLoS 2: e392, 2007.

15. Morimoto-Tomita M, Uchimura K, Bistrup A, Lum DH, Egeblad M, Boudreau N, Werb Z and Rosen SD: Sulf-2, a proangiogenic heparan sulfate endosulfatase, is upregulated in breast cancer. Neoplasia 7: 1001-1010, 2005.
16. Lemjabbar-Alaoui H, van Zante A, Singer MS, Xue Q, Wang YQ, Tsay D, He B, Jablons DM and Rosen SD: Sulf-2, a heparan sulfate endosulfatase, promotes human lung carcinogenesis. Oncogene 29: 635-646, 2010

17. Rosen SD and Lemjabbar-Alaoui H: Sulf-2: An extracellular modulator of cell signaling and a cancer target candidate. Expert Opin Ther Targets 14: 935-949, 2010.

18. Zhu C, Qi X, Chen Y, Sun B, Dai Y and Gu Y: PI3K/Akt and MAPK/ERK1/2 signaling pathways are involved in IGF-1induced VEGF-C upregulation in breast cancer. J Cancer Res Clin Oncol 137: 1587-1594, 2011.

19. Khurana A, Beleford D, He X, Chien J and Shridhar V: Role of heparan sulfatases in ovarian and breast cancer. Am J Cancer Res 3: 34-45, 2013.

20. Khurana A, McKean H, Kim H, Kim SH, McGuire J, Roberts LR, Goetz MP and Shridhar V: Silencing of HSulf-2 expression in MCF10DCIS.com cells attenuate ductal carcinoma in situ progression to invasive ductal carcinoma in vivo. Breast Cancer Res 14: R43, 2012.

21. Guo J, Huang Y, Yang L, Xie Z, Song S, Yin J, Kuang L and Qin W: Association between abortion and breast cancer: An updated systematic review and meta-analysis based on prospective studies. Cancer Causes Control 26: 811-819, 2015.

22. Scully OJ, Bay BH, Yip G and Yu Y: Breast cancer metastasis. Cancer Genomics Proteomics 9: 311-320, 2012.

23. Sun DW, Zhang YY, Qi Y, Zhou XT and Lv GY: Prognostic significance of MMP-7 expression in colorectal cancer: A metaanalysis. Cancer Epidemiol 39: 135-142, 2015.

24. Kasthuri RS, Taubman MB and Mackman N: Role of tissue factor in cancer. J Clin Oncol 27: 4834-4838, 2009.

25. Eichhorn ME, Kleespies A, Angele MK, Jauch KW and Bruns CJ: Angiogenesis in cancer: Molecular mechanisms, clinical impact. Langenbecks Arch Surg 392: 371-379, 2007.

26. Harris NC, Davydova N, Roufail S, Paquet-Fifield S, Paavonen K, Karnezis T, Zhang YF, Sato T, Rothacker J, Nice EC, et al: The propeptides of VEGF-D determine heparin binding, receptor heterodimerization, and effects on tumor biology. J Biol Chem 288: 8176-8186, 2013

27. Gu Y, Qi X and Guo S: Lymphangiogenesis induced by VEGF-C and VEGF-D promotes metastasis and a poor outcome in breast carcinoma: A retrospective study of 61 cases. Clin Exp Metastasis 25: 717-725, 2008. 